Dickinson-Delaporte, S. and Ford, J. and Gill, D. 2014. Model Looks, Motives, and Affective Outcomes. Journalism and Mass Communication Quarterly. 91 (2): pp. 357-374.

\begin{abstract}
Highly attractive models are intended to impact psychologically on message receivers and improve awareness, expectations, attitudes, beliefs, and advertising effectiveness; however, benefits accrue in only particular situations. This study examines how advertising triggers affect when comparison motive is paired with a particular model beauty type. Qualitative work preceded empirical study, which involved use of three types of model beauty (classic, sexual, and cute), two comparison motives (self-evaluation headline and self-improvement headline), and two product contexts (problem-solving and enhancement). Female university students $(N=1,170)$ were surveyed with findings indicating that viewers do react differently depending on the beauty type, with evidence of an interaction between beauty type and comparison motive.
\end{abstract}




\section{Model Looks, Motives and Affective Outcomes}

Globally, the use of highly attractive models (HAMs) in advertising remains the dominant approach when marketing beauty products. The use of HAMs is not without controversy given the evidence that HAMs can trigger negative emotions that lead to negative physiological outcomes among individuals. ${ }^{1}$ Negative affect is harmful for individuals and is also undesirable for advertisers. From an advertiser's perspective, avoiding negative affect is underscored by the knowledge that consumer acceptance of advertising is mediated by affective reactions, where positive emotions are requisite for positive advertising outcomes. ${ }^{2}$ Consequently, understanding the conditions under which negative affect can be minimized is important. For example, HAMs are able to create positive emotions when used effectively in attractivenessrelevant contexts, ${ }^{3}$ where they have credibility (knowledge, experience, or skills), ${ }^{4}$ and their physical characteristics act as an argument for product effectiveness. ${ }^{5}$ HAMs have also been shown as more effective in situations where specific model types are used $^{6}$ or when paired with particular brands/products, ${ }^{7}$ used in low-involvement situations where peripheral cues are processed, ${ }^{8}$ in emotional branding situations ${ }^{9}$ or when comparison motives are self-improvement or self-enhancement rather than evaluative. $^{10}$

Despite the quality of discussion regarding these contexts, many unanswered questions remain regarding how best to minimize negative affect among individuals' processing HAMs. Some of these questions relate to the role of model characteristics and comparison motives. Research has established that model characteristics or "looks" differ and that they stimulate variation in audience responses, ${ }^{11}$ however, 
additional research is needed relating to processing variations triggered by interactions between model type and comparison motive. ${ }^{12}$ Given that advertisers have control over message content, their creation of negative affect can be minimized if they have an understanding of the role of model type and comparison type. Minimizing the arousal of negative emotions is in the best interests of advertisers and individuals alike. Our research focuses on the following question, "Do beauty type and comparison motives interact to create variation in negative affect?" Focus group findings and quantitative data relating to processing are provided, followed by managerial implications and future research directions.

\section{Literature Review}

Negative Affect. An understanding of affective reactions is important for understanding an individual's cognitions and behaviors. ${ }^{13}$ Past research relating to affect reveals divergent opinions regarding the relationship between affect, cognitions, and behavior. Affect can indicate an instinctual reaction to stimulation and can be independent of cognitive processes, ${ }^{14}$ while others consider that affect can be a consequence of cognitive processing. ${ }^{15}$ Notwithstanding the different research findings, it is widely accepted that consumer acceptance of advertising is mediated by affective reactions, ${ }^{16}$ and that affective states stem from both the advertisement and the program context. ${ }^{17}$

Various studies have examined the consequences of negative affect on individuals $^{18}$ and advertising effectiveness. ${ }^{19}$ From an advertising perspective, negative feelings can result in message recipients engaging in derogation of the model featured in the advertising stimuli, ${ }^{20}$ as well as derogation of the model's credibility, knowledge, and expertise. ${ }^{21}$ As a result, the message arguments are not persuasive and 
become ineffective. $^{22}$ Furthermore, negative feelings can create negative attitudes towards the advertisement and the advertised brand, and can lead to negative purchase intent. ${ }^{23}$ Authors who have recently examined the consequences of using highly attractive models in advertising have noted that an empirical examination of the factors driving negative affect is needed. ${ }^{24}$

Model Characteristics. Conventionally, models are mostly conceptualized along a single continuum from "highly unattractive" to "highly attractive.", While conceptualizing beauty level is important, it does not adequately reflect variation in the type of model "look." Models can be equally attractive, yet differ in terms of physical features and qualities so that they have a defined type of "look."26

The need to examine "beauty type" as a driver of negative affect was highlighted by previous researchers ${ }^{27}$ who found that there were differences in processing when females were exposed to advertisements depicting "sexy" versus "non-sexy" models. Interestingly, while females were not able to distinguish between sexy/non-sexy models, their processing outcomes varied. That is, advertisements depicting sexy models were more unbelievable, uninformative, and confusing when compared to ads using a non-sexy message source.

Bower also suggested that model characteristics may be one explanation for the differences found pertaining to the levels of negative affect experienced and cognitive as well as behavioral outcomes. ${ }^{28}$

Goodman and his colleagues' findings ${ }^{29}$ supported Bower's suggestions and collapsed Solomon and his colleagues' findings ${ }^{30}$ of beauty types into two types of 'looks' Sexual/sensual (SS) and Cute/Classic/Girl Next Door (CCG). They found that CCG models created more positive emotional responses among women in terms of pleasure, arousal, and dominance, recommending that advertisers use more CCG 
models in their copy to stimulate purchase behavior among women. While Goodman et al. inferred from their findings that SS models may trigger upward comparisons and CCG models may trigger upward self-improvement motives creating positive feelings, these assumptions remain untested.

Social Comparison Behavior. Social comparison theory ${ }^{31}$ is commonly used as a basis for investigating how young women engage in comparison of their physical attractiveness with that of a highly attractive model. ${ }^{32}$ Numerous researchers have demonstrated that the use of HAMs in advertising has caused many women to make comparisons with idealized images of beauty and physical perfection. ${ }^{33}$ Research regarding comparison outcomes has been fragmented because researchers have examined comparison behavior generally, rather than focusing on specific motives. Evidence suggests that when a comparison takes place, differential comparison motives may occur, and in turn, these will impact the resulting level of negative affect experienced. ${ }^{34}$

Social comparison motives may occur for several reasons: self-evaluation, self-improvement, or self-enhancement. ${ }^{35}$ Research has generally acknowledged that self-evaluation is an upward comparison motive that generates negative emotions given that the comparative other is seen to be superior across important traits. ${ }^{36}$ Similarly, a self-improvement motive prompts upward comparisons with others who are considered superior; however, as the comparer is making comparisons with someone who is considered dissimilar, or an indirect competitor, the upward comparison becomes inspiring and less negative affect may result. ${ }^{37}$ Conversely, a self-enhancement motive may prompt comparisons with those who are deemed inferior (downward comparison) or, if perceived to be superior, it will be discounted on the basis of a lack of similarity to self. ${ }^{38}$ Beyond generalizations about upward and 
downward comparisons, affective consequences of a social comparison may vary depending on the manner in which information is interpreted..$^{39}$ Upward comparisons create negative affective states when people feel they have little chance of changing their (inferior) position, i.e., a lack of perceived control. ${ }^{40}$

Two of the three comparison motives are most common among female preadolescents: self-evaluation and self-improvement. ${ }^{41}$ In this study, we do not examine naturally occurring comparison motives. ${ }^{42} \mathrm{We}$ are interested upward comparisons and differences in affect when comparison motive is paired with a particular model beauty type. Bower suggested that beauty type and comparison motive may interact to create variation in negative affect. $^{43}$ Goodman and his colleagues supported this suggestion. $^{44}$

\section{Method Study 1}

To address our research question we developed stimulus materials through two rounds of stringent pre-testing, followed by a series of five focus groups using individuals from the target pool of respondents. We did so for three reasons. First, there is a lack of research relating to the interaction between beauty type and comparison motive, justifying a more exploratory approach to capture a wide range of individual responses. Second, focus group qualitative research is an effective way of capturing consumer responses to advertisements. ${ }^{45}$ Third, this study responds to Goodman and his colleagues' call for future research to "conduct focus groups to find out individual differences in response to images." 46

To select images for the study, we used Solomon and his colleagues' attractiveness types. ${ }^{47}$ That study delineated six distinct types of beauty: Classic/Feminine, Sensual/ Exotic, Cute, Girl-Next-Door, Sex Kitten, and Trendy. In 
order to develop stimulus materials, we started with 100 images of HAMs from fashion magazines and layouts. All the models chosen were of Western appearance. To further develop experimental design stimulus materials, 16 undergraduate female students were shown the 30 images that included representations of the six beauty types ${ }^{48}$ They were asked to assess whether the model was highly attractive and to indicate the likelihood of comparison behavior with each model image. ${ }^{49}$ In order for comparison behavior to occur, the image had to be rated as "highly attractive," and there had to be high levels of involvement. ${ }^{50}$ The stimulus materials required for the focus groups also needed to control for the influence of product type (whether the product in this case is considered to be a "problem solving" or an "enhancement" type of beauty product). Phase one pre-testing also involved a verification of relevant ad headline and body copy for treatment development. Comparison motives were manipulated through both headline and body copy. ${ }^{51}$

Pre-tests resulted in the selection of three model images. A second round of pre-testing was conducted to reconfirm that each image was consistently rated as highly attractive and represented a single beauty type. Only three (Classic, Sexual, Cute) of Solomon's original six beauty types were rated as highly attractive and used for consequent focus group discussions below. Finally, during this second round of pre-testing, we verified the appropriateness of the headlines and body copy. Based on the pre-test results, twelve print advertisements were finalized by a graphic designer and used as stimuli for the focus groups. Each of the three types of model beauty was developed with four different executions. For example, the Classic model was depicted with two executions for each of the two product types (facial cleanser and lip gloss) and two executions for the comparison motives (self-evaluation and selfimprovement). 
Focus Groups. Each focus group included 8-10 females aged between 17 and 28 years, with a combined total of 44 participants across all focus groups. This demographic was selected for several reasons. First, the readership profiles of top women's lifestyle magazines in Australia (c.f., Marie Claire, Cleo, Cosmopolitan, and Frankie) target females aged 17 years and upwards. Treatments used in focus groups were created from ads taken from magazines targeting this age profile. Further, the decision to focus on females under 30 years was based on the understanding that they compare their physical attractiveness with that of models in advertising, ${ }^{52}$ and the study of undergraduate female students is common in this area of research. ${ }^{5}$. The composition of each focus group was based on random assignment, included both Caucasians and Asian females, and all participants were undergraduate students. Focus groups ran for approximately 90 minutes each, during which time participants were asked initial cross-check questions to confirm the level of model attractiveness, beauty product type, level of product involvement, and whether the headlines influenced self-evaluation ("I feel confronted by it") or self-improvement ("I feel inspired by it"). These extensive quality control and manipulation checks were deemed vital for the final experiment. A semi-structured group discussion enabled probing for richer information with constant comparison data analysis so that additional codes were created as unique themes were identified. It should be noted that themes were consistently identified among Caucasians and Asian respondents and also among undergraduate students who were younger (17-24 years) compared to older students (25-28 years).

\section{Findings}


Cute Beauty. When focus group participants were shown the advertising treatment with a highly attractive model that was a "Cute" beauty type, they indicated that their level of social comparison was heightened. In fact, participants overwhelmingly stated that this was the most similar beauty type to their own and were very involved in the advertisement. Participant level of comparison was heightened due to the sense of realism that enables young women to relate most closely with this beauty type and actively process the information contained in the advertisement. Self-evaluation comparison motives were evident irrespective of product type because the participants felt this look was "similar" to themselves. The look was attainable but participants also found that they were confronted by this image more than the other images because it was so relevant. Overall, Cute models triggered moderate levels of negative affect depending on comparison motive.

Sexual Beauty. In the case of the "Sexual" beauty type, a different picture emerged. Here, the level of comparison seemed to reflect the relevance of Sexual beauty to young women; it creates interest and grabs attention. Involvement is tied to the context. Despite the ability to grab attention, advertisers should be aware that Sexual beauty featured in an advertisement creates high negative affect. This response to Sexual beauty types is likely impacted by the perception that they are associated with contexts such as night time and attracting men, and viewed as less trustworthy (fake, airbrushed) than the other two types of model beauty.

Classic Beauty. The information processing for Classic beauty seems to be different from either Cute or Sexual beauty types. Classic beauty seems to be viewed by these young women as a "distant target." Classic beauty types were seen as very 
highly attractive, but because of the inferred distance between their current self and the model depicted, young women did not feel that they needed to "tune in" to the message. That is, these young women did not want to obtain that look now; however, this type of beauty was seen as more appropriate in five to ten years from now and was consistently associated with a "30's-something" woman. Despite focus group participants acknowledging that Classic beauty is the "ultimate" in beauty, it is largely unachievable, so they were detached and had limited processing. It should also be noted that negative affect is low irrespective of a self-evaluation or selfimprovement comparison headline and irrespective of product type.

Interaction Effects: Comparison Motive and Beauty Type. When we investigated further, comparison motive appears to interact with beauty type to create variation in processing. For example, when confronting headlines were used alongside a Cute beauty asking females whether they"look this good," negative affect attenuated to moderate levels. These direct comparisons were confronting. In contrast, when Cute models were paired with inspirational headlines that motivate young women to achieve a look, they had lower negative affect. This pattern of processing was also true when the social comparison motives related to Sexual beauty. When selfevaluation comparison headlines were paired with a Sexual beauty, negative emotions seemed to be amplified irrespective of product type. In contrast, when a Sexual beauty was used with an inspirational headline, negative emotions were reduced to moderate levels. It appears that when advertisers use a Cute or Sexual beauty, they need to be wary of the type of social comparison motive they elicit among young women. Advertisers must endeavor to create inspiration and empowerment rather than stimulate a direct comparison of self. 
Comparison motives did not appear to create varied processing with a Classic beauty type. It seems that young women notice the advertisement because the model is very beautiful but may not be processing it, so that they are impervious to emotional changes.

\section{Research Hypotheses}

Several research hypotheses arise from the literature and the qualitative findings. Sexual beauty types have been found to create stronger negative emotions relative to other beauty types. Goodman and his colleagues found that Sexual/Sensual (SS) beauty creates little pleasure or arousal among message receivers relative to those classified as Classic/Cute/Girl Next Door (CCG). ${ }^{54}$ This suggests that negative emotions may stem from women attempting to avoid these types of images due to a feeling of inadequacy or even being uninterested in Sexual beauty types because of

negative associations (promiscuity and incompetence). ${ }^{55}$ Similarly, Patzer found that sexy message sources were less believable and more uninformative relative to nonsexy message sources. ${ }^{56}$

Focus group findings support the findings by previous researchers. ${ }^{57}$ That is, Sexual beauty types create stronger negative affect than Cute beauty and Classic types. One difference, however, relates to our grouping of beauty types. While Goodman et al. cluster Cute and Classic models into one group, our focus group results show that they are two distinct types and that processing variations occur. For example, Classic beauty types created low negative affect, perhaps because they received little attention from message receivers. Cute beauty types received a great deal of attention from message receivers and created low to moderate levels of negative affect as they were viewed to be realistic, achievable, and very similar to the message receiver. As a result, the following hypotheses are offered: 
H1: Among comparers, Sexual beauty types create stronger negative affect than Cute or Classic beauty types.

H2: Among comparers, Cute beauty types create stronger negative affect than Classic beauty types.

In this study, we are interested the interaction between comparison motive and model beauty type. Previous research has suggested that beauty type and comparison motive may interact to create variation in negative affect. ${ }^{58}$ Our focus group findings suggest when Cute and Sexual models are paired with a self-improvement motive, negative affect is lowered (irrespective of product type). Focus group findings also suggest that when a Sexual beauty type is depicted with a self-evaluation motive, negative is higher than for Cute of Classic models. Finally, type of comparison motives when paired with a Classic model does not appear to impact on emotional outcomes. Comparisons with Classic models are not naturally occurring and when exposed to the different comparison headlines, negative affect was unchanged. From the previous discussion, we offer the following hypotheses:

H3: Among comparers, Sexual and Cute beauty types create stronger negative affect when paired with a self-evaluation comparison than a self-improvement comparison motive.

H4: Among comparers, Classic beauty types do not create stronger negative affect when paired with a self-evaluative comparison than a self-improvement motive. 
H5: Among comparers, Sexual beauty types are perceived to create stronger negative affect when paired with a self-evaluative comparison motive than for Cute or Classic beauty types.

H6: Among comparers, Cute beauty types are perceived to create stronger negative affect when the comparison motive is self-evaluative than for Classic beauty types.

\section{Method Study 2}

Experimental Design Procedure. A post-test only with control experimental design was used to test the hypotheses. ${ }^{59}$ Given that this study examines highly attractive model beauty types in addition to comparison motives and product types with a control group, the overall factorial design is a $3 \times 2 \times 2$ with control. There are three types of model beauty (Classic, Sexual, and Cute), two comparison motive types (self-evaluation and self-improvement) and two product types (problem-solving and enhancement) along with a control group. As part of the design, respondents received either an experimental treatment with an associated questionnaire or they received no stimulus material and a specially designed control group questionnaire. In addition, the fact that individuals were randomly assigned to either a treatment group or control group meant that any differences in the comparison of two groups could be attributed to the effects of the treatment. ${ }^{60}$

Respondents. The data collection procedure for this research followed approaches used in previous studies involving highly attractive models. ${ }^{61}$ Caucasian and Asian female university students aged 18 to 30 years were selected as respondents for the study because physical attractiveness is particularly important to them. ${ }^{62}$ This 
demographic is similar to that of the focus groups and once again was selected due to the match with readership profile of top circulating women's lifestyle magazines, and because undergraduates have high levels of comparison behavior in relation to their physical attractiveness. ${ }^{63}$ An initial pilot test with 50 female undergraduate university students was conducted to cross-check manipulations and the wording of the questionnaire. The model attractiveness level and type, comparison motive, and product type (problem solving and enhancement) were confirmed with pre-testing.

For the main study, the total sample size was 1,170 students, with each student randomly assigned to one of a possible twelve treatment cells, or the control group. For each of the thirteen cells there were approximately 90 respondents. The questionnaire used previously validated scales (see Appendix 1 measures) including initial manipulation check questions to once again confirm the model beauty level, model beauty type, comparison behavior, comparison motive, and product type.

\section{Analysis}

In order to perform the analyses, the negative affect scale items were summed. The four items making up the negative affect scale demonstrated good reliability with a Cronbach Alpha coefficient of .88. The hypotheses will now be discussed in turn.

Hypothesis Testing. H1 focused on the exposure to Sexual beauty types as opposed to Cute and Classic beauty types in ad depictions creating stronger negative affect. The mean for Sexual beauty for the negative affect scale was 17.23 ( $S D=$ 5.56; $n=290)$, while the mean for Classic beauty was $15.04(\mathrm{SD}=5.24 ; n=311)$ and $17.92(\mathrm{SD}=5.28 ; n=284)$ for Cute beauty. The ANOVA showed a significant difference across the three $(\mathrm{F}=23.76, p<.001, \mathrm{df}=884)$. In order to shed further light on the differences, Tukey's Honestly Significant Differences test was run, and the results showed that the Sexual beauty exposure was significantly more negative than 
the Classic beauty ad exposure, but there was no difference between the Sexual beauty ad and the Cute beauty ad in terms of negative affect. As a result, $\mathrm{H} 1$ is only partially supported.

H2 examines specifically the comparison between Cute beauty and Classic beauty ad depictions, and from the mean scores mentioned in the discussion for H1, the negative affect associated with Cute beauty is significantly greater than that for Classic beauty $(\mathrm{F}=23.76, \mathrm{p}<.001, \mathrm{df}=884)$. As a result, $\mathrm{H} 2$ is supported.

$\mathrm{H} 3$ added the comparison motive to the analysis with the expectation that Sexual and Cute beauty types when paired with self-evaluative comparisons would create greater negative affect than for the same beauty types with self-improvement comparisons. The negative affect associated with Sexual beauty when paired with a self-evaluation comparison motive (Mean=17.74, $\mathrm{SD}=5.81$ ) is not significantly higher $(\mathrm{F}=2.548, \mathrm{p}=.112, \mathrm{df}=289)$ than the negative affect associated with Sexual beauty when paired with a self-improvement comparison motive (Mean=16.70, $\mathrm{SD}=5.24$ ); however, when Cute beauty was paired with a self-evaluation motive (Mean=19.04, $\mathrm{SD}=4.32)$, this produced significantly higher negative affect $(\mathrm{F}=12.335, \mathrm{p}=.001$, $\mathrm{df}=283$ )than Cute beauty when paired with a self-improvement motive (Mean=16.88, $\mathrm{SD}=5.86)$. In this case, $\mathrm{H} 3$ was partially supported.

H4 examined the use of Classic beauty with different comparison motives, but in this case there were no significant differences expected in negative affect. The mean for negative affect for Classic beauty with a self-evaluation comparison motive (Mean=15.46, $\mathrm{SD}=5.33)$ was not significantly different $(\mathrm{F}=1.967, \mathrm{p}=.162, \mathrm{df}=310)$ from the mean for negative affect for Classic beauty with a self-improvement comparison motive (Mean=14.63, $\mathrm{SD}=5.13$ ). As expected, $\mathrm{H} 4$ was supported. 
H5 focused on Sexual beauty when paired with a self-evaluative comparison motive potentially creating greater negative affect than for either Cute beauty or Classic beauty when paired with the same comparison motive. In this case the mean for Sexual and self-evaluative comparison (Mean=17.74, SD=5.81) was significantly greater $(\mathrm{F}=17.447, \mathrm{p}=.000, \mathrm{df}=435)$ than for Classic beauty with a self-evaluative comparison motive (Mean=15.46, $\mathrm{SD}=5.33$ ), but it is significantly less (in this case the Tukey's analysis indicated significantly greater negativity for cute than for sexual and also significantly greater negativity for sexual than for classic) than the negative affect created by combining Cute beauty with a self-evaluative comparison motive (Mean=19.04, $\mathrm{SD}=4.32$ ). As a result, $\mathrm{H} 5$ is only partially supported.

Finally, H6 examined the creation of negative affect for Cute beauty when combined with a self-evaluative comparison motive (Mean=19.04, $\mathrm{SD}=4.32$ ) when compared with the negative affect created by combining Classic beauty with a selfevaluative comparison motive (Mean=15.46, $\mathrm{SD}=5.33$ ). The difference was significant $(\mathrm{F}=17.447, \mathrm{p}=.000, \mathrm{df}=435)$, and the expected difference was found. Thus, H6 was supported.

In summary, three of the six hypotheses were fully supported, while three were only partially supported.

\section{Discussion}

So what do these results mean? Viewers react differently depending on the beauty type. Cute beauty types create the highest levels of negative affect with evidence of an interaction between beauty type and comparison motive. Contrary to findings by previous researchers, ${ }^{64}$ Sexual beauty depictions did not cause the highest level of negative affect. Qualitative results shed light on the reason why Cute models may generate high levels of negative emotion. Cute models are perceived as similar to 
their audience's "self" so that direct evaluations against this type of model are immediate and naturally occurring. Cute model characteristics include being "natural" and "genuine," which make the advertising executions highly believable. As such, comparing one's self against this type of model creates upward comparisons that are highly evaluative and create high negative affect. Qualitative findings suggest that negative affect triggered by Sexual beauty types may be occurring for different reasons. Once again, there are high levels of involvement and extensive comparison behavior among women, however, Sexual beauties are thought to be "overly made up," so there is a level of skepticism (e.g., "the image is airbrushed"). Patzer ${ }^{65}$ also provides rationale for negative affect attributed to Sexual models based on Learning Theory ${ }^{66}$ and Consistency Theory. ${ }^{67}$ For example, sexiness is likely frowned upon and discouraged by parents when their children are young and this will lead to perceptions of competitive threat from sexual images. Similarly, Patzer uses Consistency Theory ${ }^{68}$ to suggest that because sexiness is likely to be viewed negatively over time, this is then consistently applied to an advertising treatment.

Our results are consistent with Goodman and his colleagues' research findings, ${ }^{65}$ which found that Sexual beauty types created strong negative affect; however, the strength of negative emotion in relation to Cute models was unexpected and differs from the results of previous researchers. ${ }^{66}$ This is likely based on the difference in our groupings. While Goodman et al. grouped Cute/Classic/Girl Next Door into a single type our classification, our cross-checks confirmed that Cute, Sexual, and Classic were independent types, which is valuable considering the extent of negative affect directed towards Cute models as revealed in the data. Our classifications also allow us to give attention to Classic models, where we again see further processing variations. Despite being rated as the most highly attractive 
models, these models did not create high levels of negative affect because the audience did not engage with the look.

Our findings go one step further. It appears that there is limited interaction between beauty type and comparison motives. Only Cute models create significantly higher negative affect when paired with an evaluative (confronting) headline that encourages a direct evaluative comparison. In this situation, negative affect is significantly higher. This was not true for Sexual or Classic beauty types. Qualitative insights suggest that when it comes to Cute models, the perceived similarity between the model and the audience is driving the strong negative emotions among viewers. Encouraging direct self-evaluation causes the highest level of negative affect. In contrast, the inspiring headline that motivates the viewer to improve is effective at reducing negative affect.

We did not find a similar relationship for Sexual models and comparison motives. While negative affect was reduced when a Sexual beauty was paired with an inspiring message, this was not statistically significant. A possible explanation could be that that the Sexual beauty stimulates comparison behavior; however, negative affect remains high irrespective of headline because inferred characteristics may override the headline. Given the extent of scepticism and disbelief associated with a Sexual beauty, perhaps the advertising message (comparison headline) is discounted and consequently creates little impact on processing. This requires further investigation. Finally, as expected, there is no interaction effect for comparison motive and model type in the context of Classic beauty. There is a lack of involvement with this beauty type, and consequently processing is limited.

Overall, exposure to HAMs does heighten negative affect, with Cute and Sexual beauty types creating the highest levels of negative affect. One may incorrectly 
infer, then, that using Classic beauties would be the more effective beauty type to use in advertising depictions as they minimize negative affect. However, this is only part of the story given Classic beauty types may not trigger high levels of negative affect because comparison with the models is reduced, and therefore processing is limited.

\section{Managerial Implications}

The issue of advertising agency ethics regarding the use of HAMs in advertising continues to be questioned by academics ${ }^{67}$ and is often a topic in the popular press. Advertising has been broadly criticized for its promotion of materialism and persuasion, ${ }^{68}$ and as being overly dominant in setting societal values $^{69}$. The reality is that companies spend hundreds of billions of dollars on advertising targeting individuals. HAMs remain the dominant approach to the advertising beauty products, with Dove being the only notable organization to employ normally attractive models (NAMs) in their beauty campaigns. The same can be said for the marketing of other image-based products such as jewellery and fashion. Certainly, NAMs have been found to attract consumers yet minimize negative affect $^{70}$; however, NAMs are not the dominant approach when marketing beauty products.

Considering that HAMs will continue to be used in the marketing of beauty products, insights from advertising researchers concerning the antecedents of negative affect can help create a unified effort regarding its avoidance. Avoidance of negative affect is central to positive outcomes, and this Australian study has opened the door for advertisers to avoid brand image disconnections and also to minimize the creation of negative psychological outcomes for individuals. The strategic value here is that if advertisers use the right type of female model and stimulate appropriate comparison 
motives, overall affect can be improved - this is good for advertisers and individuals alike. This understanding on how to use female models as a way of attracting attention to a brand while supporting positive psychological states of individuals can provide a way forward for advertisers in an industry where it is clear that there will be continued use of HAMs in advertising.

\section{Limitations and Future Research Directions}

A study of this type, which attempts to explicate the complexities and dynamic nature of negative affect when using HAMs in advertising, is bound by several limitations. This study is restricted by its cross-sectional design. It is highly plausible that the short-term effects associated with the use of HAMs in advertising accumulate resulting in higher levels of negative affect over the long term. ${ }^{71}$ A longitudinal study is needed to investigate the impact of exposure to HAMs over time. Further, three types of model beauty were investigated in this study, and yet, Englis and his colleagues identified six types of model beauty. ${ }^{72}$ The types of model beauty were based on pre-defined descriptions as per Englis and his colleagues. ${ }^{73}$ These descriptions presuppose that different ethnic groups interpret the meaning of "Classic," "Sexual," and "Cute" beauty types in a similar manner. Future research could incorporate the remaining types of model beauty to establish whether any different processing behaviors occur and their subsequent impact on negative affect. To ensure consistency of each different type of model beauty, future research also needs to confirm cultural descriptions of the type of model beauty. Also, in relation to processing variations for each type of model beauty, we relate conclusions to processing motivation ${ }^{74}$; however, this study did not use scales to determine processing motivation (i.e., central route versus peripheral route processing after exposure to each beauty type). More work is clearly warranted. 
A further limitation relates to the respondents investigated in this study (female university students aged between 18 and 30 years). It is highly likely that the negative affect phenomenon tested in this study is not only limited to this demographic group but would also extend to different age groups of females. It would also be prudent to test additional product categories beyond beauty products as information processing may vary for the use of different types of model beauty paired with various classes of consumer durables.

Finally, this research has not addressed the impact of exposure to HAMs on an individual's self-perception, self-esteem or self-concept, nor whether these factors moderate the relationship between comparison levels and negative affect. It would be interesting to see whether variations in results could stem from the use of attractiveness types and interaction effects with comparison motivations. 


\section{Appendix}

Measures. The level of model beauty, social comparison, negative affects and product argument were measured through the use of validated scales. ${ }^{75}$ Model beauty was addressed with three items to determine whether the model used in the treatment advertisements reflected a typical HAM (e.g., "This model's superior beauty would stand out among other models in a magazine"). ${ }^{76}$ Respondents rated their level of agreement on a 7 -point scale $(1=$ strongly disagree, $7=$ strongly agree $)$. The manipulation check showed that respondents rated the model as being as beautiful as other HAMS in advertising. Type of model beauty was used as a manipulation check, and a question was added to the questionnaire which involved a verification of the beauty type involved in the treatment (e.g., "Would you classify this model's beauty type/look as: Cute/Sexual/Classical/other"). Finally, subject comparison motive was added to the questionnaire as a cross check to verify whether headlines had triggered self-evaluation or a self-improvement comparison (e.g., "I feel confronted/inspired").

The level of subject comparison with the highly attractive model was measured using three Likert-type items (e.g., "If you noticed this advertisement in a magazine filled with images of highly attractive models, how likely is it that you would compare yourself to the model?"). Respondents rated their level of agreement on a 7 -point scale ( $1=$ extremely unlikely, $7=$ extremely likely). The reliability for this construct scale was found to be appropriate for our analysis with a Cronbach Alpha .77.

Negative affect was measured using four Likert-type items based on the work of Folkman ${ }^{77}$ and replicated by Bower. ${ }^{78}$ Two of the items used in this study were direct replications (“Advertisements such as this one sometimes make me feel anxious 
about my appearance" and "Advertisements like this one sometimes make me feel frustrated."). Pilot test findings resulted in minor changes to the two remaining items: "Advertisements like this can sometimes negatively influence how I feel about myself" and "Sometimes I feel resentful when I encounter advertisements like this one." The word "sometimes" was inserted for consistency with the first two items and because it was noted that pilot test respondents did not always feel negative when viewing advertisements. Respondents rated their level of negative affect on a 7-point scale $(1=$ strongly disagree, $7=$ strongly agree). The reliability for the construct of negative affect was considered appropriate for our analysis at an alpha of .88. 


\section{Reference List}

1. Lori M. Irving, "Mirror Images: Effects of the Standard of Beauty on the Self-and Body Esteem of Women Exhibiting Varying Levels of Bulimic Symptoms," Journal of Social and Clinical Psychology 9 (2, 1990): 230-42; Dave Perry, "Research Advances of the '80s Help Advertisers in the '90s," Marketing News 26 (4, 1992): 4-5; Heidi D. Posovac, Steven S. Posovac, and Richard G. Weigel, "Reducing the Impact of Media Images on Women at Risk for Body Image Disturbance: Three Targeted Interventions," Journal of Social and Clinical Psychology 20 (3, 2001): 324-41.

2. Peter L. Wright, "The Cognitive Processes Mediating Acceptance of Advertising," Journal of Marketing Research 10 (1, 1973): 53-62.

3. Susi Geiger and Amy Fennell, "Beauty or the Beast? Attractive Spokespeople in Chocolate Advertisements," European Advances in Consumer Research 6 (1, 2003): 110-14; Amanda B. Bower and Stacy Landreth, "Is Beauty Best? Highs versus Normally Attractive Models in Advertising," Journal of Advertising 30 (1, 2001): 1-12; Lynn R. Kahle and Pamela M. Homer, "Physical Attractiveness of Celebrity Endorser: A Social Adaptation Perspective," Journal of Consumer Research 11 (4, 1985): 954-61.

4. Judson Mills and John Harvey, "Opinion Change as a Function of When Information about the Communicator is Receiver and Whether He is Attractive or Expert," Journal of Personality and Social Psychology 21 (1, 1972): 52-55; Jo A. Horai, Nicholas Naccari, and Elliot Fatoullah, "The Effects of Expertise and Physical Attractiveness upon Opinion Agreement and Liking," Sociometry 37 (4, 1974): 601606; James Maddux and Ronald Rogers, "Effects of Source Expertness, Physical Attractiveness, and Supporting Arguments on Persuasion: A Case of Brains Over Beauty," Journal of Personality and Social Psychology 39 (2, 1980): 235-44; Roobina Ohainian, "Construction and Validations of a Scale to Measure Celebrity Endorsers' Perceived Expertise, Trustworthiness, and Attractiveness," Journal of Advertising 19 (3, 1990): 39-53.

5. Kahle and Homer, "Physical Attractiveness of Celebrity Endorser"; Paul W. Miniard, Sunil Bhatla, Kenneth R. Lord, Peter R. Dickson, and Rao H. Unnava, "Picture Based Persuasion Processes and the Moderating Role of Involvement," Journal of Consumer Research 18 (1, 1991): 92-107.

6. Robyn J. Goodman, Jon D. Morris, and John C. Sutherland, "Is Beauty A Joy Forever? Young Women's Responses To Varying Types of Beautiful Advertising Models," Journalism and Mass Communication Quarterly 85 (1, 2008): 147-68.

7. Michael R. Solomon, Richard D. Ashmore, and Laura C. Longo, "The Beauty Match-Up Hypothesis: Congruence between Types of Beauty and Product Images in Advertising," Journal of Advertising 21 (4, 1992): 23-34.

8. Maddux and Rogers, "Effects of Source Expertness."

9. Maddux and Rogers, "Effects of Source Expertness."

10. Mary C. Martin and James W. Gentry, "Stuck in the Model Trap: The Effects of Beautiful Models in Ads on Female Pre-Adolescents and Adolescents," Journal of Advertising 26 (2, 1997): 19-33. 
11. Solomon, Ashmore, and Longo, "The Beauty Match-Up Hypothesis"; Richard D. Ashmore, Michael R. Solomon, and Laura C. Longo, "Thinking about Fashion Models' Looks: A Multidimensional Approach to the Structure of Perceived Physical Attractiveness," Personality and Social Psychology Bulletin 22 (11, 1996), 1083; Gordon Patzer, "A Comparison of Advertisement Effects: Sexy Female Communicator VS Non-Sexy Female Communicator," Advances in Consumer Research 7 (1, 1980): 359-64; Goodman, Morris, and Sutherland, "Is Beauty A Joy Forever?"

12. Amanda B. Bower, "Highly Attractive Models in Advertising and the Women Who Loathe Them: The Implications of Negative Affect for Spokesperson Effectiveness," Journal of Advertising 30 (3, 2001): 51-64; Goodman, Morris, and Sutherland, "Is Beauty A Joy Forever?"

13. Rajeev Batra and Michael L. Ray, "Affective Responses Mediating Acceptance of Advertising," Journal of Consumer Research 13 (2, 1986): 234-50; Andrew B. Aylesworth, Ronald C. Goodstein, and Ajay Kalra, "Effect of Archetypal Embeds on Feelings: An Indirect Route to Affecting Attitudes," Journal of Advertising 28 (3, 1999): 73-81.

14. Chris Janiszewski, "Preconscious Processing Effects: The Independence of Attitude Formation and Conscious Thought," Journal of Consumer Research 15 (2, 1988): 199-209; Robert B. Zajonc, "Feeling and Thinking: Preferences Need No Inferences," American Psychologist 35 (2, 1980): 151-75.

15. Richard S. Lazarus, "Thoughts on the Relations between Emotions and Cognition," American Physiologist 37 (9, 1982): 1019-24.

16. Wright, "The Cognitive Processes Mediating Acceptance of Advertising."

17. Jacob Cohen, "Attitude, Affect and Consumer Behaviour," in Affect and Social Behavior, ed. Bert S. Moore and Alice M. Isen (Cambridge: Cambridge University Press, 1990), 152-206.

18. Irving, "Mirror Image."; Perry, "Research Advances."; Posovac, Posovac, and Weigel, "Reducing the Impact."

19. Aylesworth, Goodstein, and Kalra, "Effect of Archetypal Embeds on Feelings."; Bower, "Highly Attractive Models in Advertising."

20. Peter Salovey and J. Rodin, "Some Antecedents and Consequences of Social-Comparison Jealousy," Journal of Personality and Social Psychology 47 (4, 1984): 780-92.

21. Robert B. Cialdini and Kenneth Richardson, "Two Indirect Tactics of Image Management: Basking and Blasting," Journal of Personality and Social Psychology Research 39 (3, 1980): 406-15; Salovey and Rodin, "Some Antecedents and Consequences of Social-Comparison Jealousy."

22. Bower, "Highly Attractive Models in Advertising."

23. Aylesworth, Goodstein, and Kalra, "Effect of Archetypal Embeds on Feelings."; Bower, "Highly Attractive Models in Advertising."

24. Bower, "Highly Attractive Models in Advertising."; Bower and Landreth, "Is Beauty Best?" 
25. George E. Belch, Michael A. Belch, and Anjelina Villareal, "Effects of Advertising Communications: Review of Research," Research in Marketing 9 (1, 1987): 59-117; Bower, "Highly Attractive Models in Advertising."; Bower and Landreth, "Is Beauty Best?"; Joseph W. Benoy, "The Credibility of Physically Attractive Communicators: A Review," Journal of Advertising 11 (3, 1982): 15-24; Martin and Gentry, "Stuck in the Model Trap."; Marsha L. Richins, "Social Comparison and the Idealized Images of Advertising," Journal of Consumer Research 18 (1, 1991): 71-83; Martha L. Richins, "Social Comparison, Advertising and Consumer Discontent. Social Advocacy: Marketing and Consumer Behavior Research in the Public Interest," American Behavioral Scientist 38 (4, 1995): 593-607.

26. Solomon, Ashmore, and Longo pioneered much of the work in the field of female beauty research by proposing that perceivers distinguish multiple types of model beauty. Cultural gatekeepers (fashion and beauty editors) participated in a free card-sorting exercise where they were asked to sort images of females models based on the similarity of looks. Sorting data was analyzed using multi- dimensional scaling to provide empirical validation of distinct beauty types. The researchers developed six distinct "looks": Classic/Feminine, Sensual/Exotic, Cute, Girl Next Door, Sex Kitten and Trendy; Solomon, Ashmore, and Longo, "The Beauty MatchUp Hypothesis."

27. Patzer, "A Comparison of Advertisement Effects."

28. Bower, "Highly Attractive Models in Advertising."

29. Goodman, Morris, and Sutherland, "Is Beauty A Joy Forever?"

30. Solomon, Ashmore, and Longo, "The Beauty Match-Up Hypothesis."

31. Leon Festinger, "A Theory of Social Comparison Processes," Human Relations 7 (2, 1954): 117-40.

32. Festinger, "A Theory of Social Comparison Processes."; Mary C. Martin and Patricia F. Kennedy, "Advertising and Social Comparison: Consequences for Female Pre-Adolescents and Adolescents," Psychology and Marketing 10 (6, 1993): 513-30; Richins, "Social Comparison and the Idealized Images of Advertising."; Richins, "Social Comparison, Advertising and Consumer Discontent."

33. Christina N. Baker, "Images of Women's Sexuality in Advertisements: A Content Analysis of Black and White-oriented Women's and Men's Magazines," Sex Roles 52 (1, 2005): 13-7; Charles S. Gulas and Kim McKeage, "Extending Social Comparison: An Examination of the Unintended Consequences of Idealized Advertising Imagery," Journal of Advertising 29 (2, 2000): 17-28; Heather Patrick, Clayton Neighbours, and Raymond Knee, "Appearance-Related Social Comparisons: The Role of Contingent Self-esteem and Self-perceptions of Attractiveness," Personality and Social Psychology Bulletin 30 (4, 2004): 501-14; Joann Peck and Barbara Loken, "When Will Larger-Sized Female Models in Advertisements Be Viewed Positively? The Moderating Effects of Instructional Frame, Gender and Need for Cognition," Psychology and Marketing 21 (6, 2004): 425-42; Donnalyn Pompper and Jesica Koenig, "Cross-Cultural Generational Perceptions of Ideal Body Image: Hispanic Women and Magazine Standards," Journalism and Mass Communication Quarterly 81 (1, 2004): 89-107. 
34. Bower, "Highly Attractive Models in Advertising."; Martin and Gentry, "Stuck in the Model Trap."

35. Joanne V. Wood, "Theory and Research Concerning Social Comparisons and Personal Attributes," Psychological Bulletin 106 (2, 1989): 231-48;

Martin and Gentry, "Stuck in the Model Trap."

36. Wood, "Theory and Research Concerning Social Comparisons and Personal Attributes."

37. Wood, "Theory and Research Concerning Social Comparisons and Personal Attributes."

38. T. A. Wills, "Downward Comparison Principles in Social Psychology," Psychological Bulletin 90 (2, 1981): 245-71.

39. Phillip Brickman and Ronnie J. Bulman, "Pleasure and Pain in Social Comparison," In Social Comparison Processes: Theoretical and Empirical Perspectives, ed. J. M. Suls and R. L. Miller (Washington, DC: Hemisphere, 1977), 149-86; Bram P. Buunk, R. L. Collins, Shelley E. Taylor, N. W. Van Ypren, and Gayle A. Dakof, "The Affective Consequences of Social Comparison: Either Direction Has Its Ups and Downs," Journal of Personality and Social Psychology 59 (6, 1990): 1238-49; Shelley. E. Taylor and Marci Lobel, "Social Comparison Activity under Threat: Downward Evaluation and Upward Contacts," Psychological Review 96 (4, 1989): 569-75; Abraham. Tesser, "Towards a Self-Evaluation Maintenance Model of Social Behaviors," in Advances in Experimental Social Psychology, ed. Leonard. Berkowitz (San Diego, CA: Academic Press, 1988), 181-227.

40. Maria Testa and Brenda Major, "The Impact of Social Comparison After Failure: The Moderating Effects of Perceived Control," Basic and Applied Social Psychology 11 (2, 1990): 205-18; Jan F. Ybema and Bram P. Bunk, "Affective Responses to Social Comparison: A Study Among Disabled Individuals," British Journal of Social Psychology 34 (3, 1995): 279-92.

41. Martin and Kennedy, "Advertising and Social Comparison."

42. Martin and Gentry, "Stuck in the Model Trap."

43. Bower, "Highly Attractive Models in Advertising."

44. Goodman, Morris, and Sutherland, "Is Beauty A Joy Forever?"

45. Geiger and Fennell, "Beauty or the Beast?"

46. Goodman, Morris, and Sutherland, "Is Beauty A Joy Forever?"

47. Solomon, Ashmore, and Longo, "The Beauty Match-Up Hypothesis."

48. Ashmore, Solomon, and Longo, "Thinking about Fashion Models' Looks.”; Basil G. Englis, Michael R. Solomon, and Richard D. Ashmore, "Beauty Before the Eyes of Beholders: The Cultural Encoding of Beauty Types in Magazine Advertising and Music Television," Journal of Advertising 23 (2, 1994): 49-64; Mary C. Martin and Cara O. Peters, "Exploring Adolescents Girls' Identification of Beauty Types through Consumer Collages," Journal of Fashion and Marketing and Management 9 (4, 2005): 391-406.

49. Goodman, Morris, and Sutherland, "Is Beauty A Joy Forever?"

50. Solomon, Ashmore, and Longo, "The Beauty Match-Up Hypothesis." 
51. Solomon, Ashmore, and Longo, "The Beauty Match-Up Hypothesis."

52. Martin C. Martin and Patricia F. Kennedy, "The Measurement of Social Comparison to Advertising Models: A Gender Gap Revealed," in Gender Issues and Consumer Behaviour, ed. Janeen Arnold Costa (Beverley Hills, CA: Sage Publications, 1994), 104-24; Richins, "Social Comparison and the Idealized Images of Advertising."

53. Gordon Patzer, "A Comparison of Advertisement Effects: Sexy Female Communicator VS Non-Sexy Female Communicator", Advances in Consumer Research 7 (1, 1980): 359-64; Goodman, Morris, and Sutherland, "Is Beauty A Joy Forever?"

54. Goodman, Morris, and Sutherland, "Is Beauty A Joy Forever?"

55. Carolyn Latteier, Breasts: The Women's Perspective of an American Obsession (New York: The Haworth Press, 1998).

56. Patzer, "A Comparison of Advertisement Effects."

57. Goodman, Morris, and Sutherland, "Is Beauty A Joy Forever?"; Patzer, "A Comparison of Advertisement Effects."

58. Bower, "Highly Attractive Models in Advertising."; Goodman, Morris, and Sutherland, "Is Beauty A Joy Forever?"

59. Joel Davis, Advertising Research: Theory and Practice (New Jersey, Prentice Hall, 1997).

60. Davis, "Advertising Research: Theory and Practice."

61. Bower, "Highly Attractive Models in Advertising."

62. Richins, "Social Comparison and the Idealized Images of Advertising."

63. Martin and Kennedy, "Advertising and Social Comparison."; Richins, "Social Comparison and the Idealized Images of Advertising."

64. Patzer, "A Comparison of Advertisement Effects"; Goodman, Morris, and Sutherland, "Is Beauty A Joy Forever?"

65. Goodman, Morris, and Sutherland, "Is Beauty A Joy Forever?"

66. Goodman, Morris, and Sutherland, "Is Beauty A Joy Forever?"; Patzer, "A Comparison of Advertisement Effects."

67. Martin and Gentry, "Stuck in the Model Trap."

68. Cohen, "Attitude, Affect and Consumer Behaviour."

69. Richard Pollay, "The Distorted Mirror: Reflections of the Unintended Consequences of Advertising," Journal of Marketing 50 (2, 1986): 18-36.

70. Bower and Landreth, "Is Beauty Best?"; Kahle and Homer, "Physical Attractiveness of Celebrity Endorser."

71. Martin and Kennedy, "Advertising and Social Comparison."

72. Englis, Solomon, and Ashmore, "Beauty before the Eyes of Beholders."

73. Englis, Solomon, and Ashmore, "Beauty before the Eyes of Beholders."

74. Shelly Chaiken, "Heuristic versus Systematic Information Processing and the Use of Source versus Message Cues in Persuasion," Journal of Personality and Social Psychology 39 (5, 1980): 752-66.

75. Bower, "Highly Attractive Models in Advertising." 
76. $\quad$ Bower, "Highly Attractive Models in Advertising."

77. Susan Folkman "Personal Control and Stress and Coping Processes: A Theoretical Analysis," Journal of Personality and Social Psychology 46 (4, 1984): 83952.

78. $\quad$ Bower, "Highly Attractive Models in Advertising." 